\title{
Jesuítas portugueses no Paraná: uma contribuição para a história da expansão territorial do Brasil
}

Portuguese Jesuits in Parana: A historical contribution to the study of the territorial expansion of Brazil

Regina Maria A. F. Gadelha*

\section{Resumo}

Atravessada em tempos imemoriais por indígenas, a origem do Estado do Paraná-Brasil, pode ser encontrada na confluência cultural Tupi-Guarani e na herança dos jesuítas luso-espanhóis que devassaram o território e marcaram sua história. Zona de trânsito e passagem de viajantes que se dirigiam de São Vicente para o Paraguai e o Rio da Prata, o Paraná encontra-se ligado à história da conquista e ocupação colonial portuguesa, palco de lutas entre espanhóis e portugueses. O artigo mostra como aos missionários da Companhia do Brasil se deve os primeiros contatos com os Guaranis e Kaingangs do litoral. Cartas Jesuítas mostram a presença de padres portugueses em missões anuais itinerantes na região, mesmo após a transmigração das reduções dos jesuítas espanhóis do Paraná, ao longo da segunda metade do século XVII. Desta forma, os padres da Companhia do Brasil abriram caminho para a ocupação açoriana portuguesa na região, antes de 1680.

\section{Palavras Chave}

Ocupação territorial luso-brasileira - índios e jesuítas - reduções guarani - missões itinerantes - Companhia de Jesus.

\begin{abstract}
Since immemorial times, crossed by Indians, the State of Parana - Brazil and its origins could be founded by the cultural confluence of Tupi-Guarani people and Jesuits heritage of Luso-Hispanic that were trespassed their territory and imprinted their history. Zones

\footnotetext{
* Doutora em História. Professora Titular do Departamento de Economia-FEA-PUC/SP. rgadelha@pucsp.br. Conferência realizada no Seminário Internacional Indígenas, Missionários e Espanhóis: O Paraná no contexto da Bacia do Prata-Séculos XVI e XVII, promovido pela Secretaria de
} Estado da Cultura do Governo do Paraná. Curitiba, 15 a 17 de Outubro de 2008.
\end{abstract}


of traffic and travelers passage that gone towards São Vicente to Paraguay and Plate River, Parana was connected to the conquest history of Portuguese Colonial Occupations, stages for play and fights between Portuguese and Hispanics. This paper shows how the missionaries of Company of Brazil made their first contacts with the Guarani and the Coast Kaigangs people. The Jesuit letters reveals the presence of Portuguese Priests in the annual itinerant missions at the region, even after the transmigration of the Hispanic Jesuits reductions at Parana, during the second half of the XVII century. It therefore, the Company of Brazil priests led the way to the Azorean Portuguese occupation in the region, before 1680 .

\section{Key-Words}

Luso-Brazilian Territorial Occupation - Guarani Indians and Jesuits - Guarani reductions - itinerants missions - Company of Jesus: Brazil and Paraguay.

Recibido: 10 de mayo de 2013

Evaluado: 18 de junio de 2013 


\section{Introdução}

Indígenas, missionários e espanhóis, o drama levanta uma indagação. Seria o Paraná espanhol ou espanhol-português? Penso que a origem do Paraná, antigo Guairá, deva ser procurada não só na confluência dos encontros culturais e confrontos dos TupiGuaranis, como na herança deixada pela presença dos jesuítas, dos luso-espanhóis e açorianos, que devassaram este território e marcaram a sua história. Zona de trânsito e passagem obrigatória dos viajantes que se dirigiam das costas brasileiras para o Paraguai e Rio da Prata, o Paraná encontra-se indelevelmente ligado à história da conquista e ocupação colonial, palco de lutas entre conquistadores espanhóis e portugueses pelo domínio de suas terras. Página da História política, certamente. Mas também da história econômica e cultural das trocas e comércio, a marcar alianças e neutralidades. Trata-se de temas já abordados em trabalhos de competentes colegas e especialistas missioneiros. O que permite realizar uma exposição menos detalhada de fatos, seguramente conhecidos, para procurar contribuir sobre as razões da coroa de Portugal haver apoiado as incursões dos brasílico-portugueses às terras paraguaias, contrariando os limites estabelecidos pelo Tratado de Tordesilhas.

A história da ocupação da bacia do Paraná se prende à conquista do Paraguai e à ocupação dos territórios Guarani pelos espanhóis. É bem conhecida a história das bandeiras paulistas que assaltaram as reduções e expulsaram os jesuítas e seus neófitos, sucessivamente do Guairá, do Itatim, do Tape e do Uruguai.

Quando, em 1974, iniciei as primeiras pesquisas sobre o Guairá e o Itatim, ainda eram escassos os estudos sobre as estruturas do Paraguai colonial, ligados à história missioneira da ocupação destes territórios. Entre as obras que contribuíram para a minha formação, sempre destaco as do historiador português Jaime Cortesão, em especial sobre o bandeirante Antônio Raposo Tavares e a formação territorial do Brasil (1966).

A monumental produção deste grande historiador encontra-se embasada em extensa pesquisa documental e sólidos conhecimentos geopolíticos. Cortesão realizou o primeiro levantamento das fontes documentais do importante arquivo do Ministério de Relações Exteriores (Itamarati) e em sua Mapoteca. Como Diretor da Biblioteca Nacional do Rio de Janeiro, deu continuidade aos trabalhos de Capistrano de Abreu, ao publicar a maior parte dos documentos jesuítas que constituem o fundo mais importante desta biblioteca, os manuscritos da famosa Coleção Pedro de Angelis. O resultado destes trabalhos foi a publicação dos documentos e mapas do acervo do Itamarati para a história da formação das fronteiras do Brasil, publicados entre 1965 e 1971 sob o nome de História do Brasil nos Velhos Mapas, além da vasta documentação que compõe as publicações sobre os Bandeirantes Paulistas e o Tratado de Madri, documentos do Brasil e Portugal. Dele, ainda, é a publicação em três volumes, acompanhados de Prólogo e Introdução analítica, dos documentos da Biblioteca d'Ajuda e Arquivo do Tombo, de Lisboa, intitulados Pauliceae Lusitana Monumenta Histórica.

Esta documentação permitiu a Cortesão estabelecer e comprovar sua tese acerca da legitimidade do território do Brasil se assentar no amplo espaço unitário geográfico de sua conformação. Para ele, a posição e o espaço do Estado brasileiro explicam-se de forma recíproca, graças à confluência de fatores geográficos e políticos que facilitaram a penetração e a ocupação dos lusos-brasileiros no sul do Brasil, ainda no século XVII, posse consolidada no século XVIII. Reconhecendo a unidade da toponímia do território, chama a atenção para o fato de aqui o relevo e a hidrografia contrastarem com a realidade da verdadeira fronteira continental, representada pelos contrafortes da

6 Regina Maria A. F. Gadelha. Jesuítas portugueses do Paraná... : 4-23. 
cordilheira andina, que cortam os domínios meridionais da América espanhola e a separam da América portuguesa.

Este aspecto já havia sido assinalado por Euclides da Cunha, quando chefiava os trabalhos de demarcação do Acre. Em artigo publicado no jornal O Estado de São Paulo (14/05/1904), demonstra como a muralha repressora desta cordilheira era, de fato, o maior obstáculo à penetração dos espanhóis na Amazônia e o principal fator de isolamento de que sofriam os Estados do Peru e da Bolívia atuais ${ }^{1}$. E, embora eu desconhecesse então estes artigos, observávamos em tese de 1977, sobre as estruturas do Paraguai colonial, que o isolamento das áreas do Paraguai, da Argentina e do Rio da Prata, no subcontinente sul-americano, era conseqüência de contingenciamentos não só políticos como também geográficos ${ }^{2}$. O que explicaria também a atração que tiveram os colonos paraguaios em direção ao Brasil, efetivando alianças com os paulistas, mesmo quando estes, penetrando pelos campos do Paraná, arrasaram as florescentes reduções jesuíticas do Guairá e do Itatim e empurraram os padres e seus neófitos para o Uruguai e pampas rio-grandenses.

Inúmeros autores se debruçaram sobre o tema das bandeiras, ressaltando a comunicação e os contactos entre as populações pré-colombianas do Brasil e do Paraguai, através das trilhas do Tape Aviru ou Piabiru Tupi-Guarani - chamada Estrada Real pelos portugueses ${ }^{3}$. No século XVI estas trilhas conduziam por terra e por rios, índios, missionários e colonizadores, desde São Vicente até Assunção e vice-versa. Sem falar na atração que exercia sobre os comerciantes, contrabandistas e aventureiros, atraídos pela prata de Potosi. O que, sem dúvida, influenciou nas decisões políticas dos governadores e monarcas espanhóis, levando-os a impedir a abertura destes caminhos (e povoamento) impetrados por Domingo Martinez de Irala e seus sucessores, na tentativa de salvar os esforços pioneiros destas conquistas e livrando os colonos do isolamento a que se achariam condenados no interior das terras do Paraguai.

Entretanto, contrariando as proibições da Coroa espanhola, a realidade geográfica se impunha, favorecendo a expansão portuguesa. Cortesão percebeu a importância da geografia para a unidade territorial desta parte do continente ligado através da proximidade das duas maiores bacias hidrográficas do planeta - a amazônica e a platina. Nestas, as nascentes e afluentes se estendem de norte a sul, quase a se tocarem, uma paralela à outra, para o norte e para o sul, de forma vertical, ambas correndo em direção ao Atlântico. As duas, completadas pela bacia do rio São Francisco no litoral, foram responsáveis pela relativa facilidade de deslocamento e integração dos homens no espaço brasileiro. Porém, antes mesmo da chegada dos europeus, os ameríndios varavam o território por terra e por canoas, passando de um rio a outro através da região comum às respectivas vertentes dos afluentes formadores do Amazonas e do Prata. Cortesão ilustra o processo no Mapa acompanhado do título "Faixas ou Centros Formadores de Fronteiras". (mapa 1). Escreve: "Sobre esse espaço continental, situado nos trópicos úmidos e rodeado insularmente pelo sistema hidrográfico platino-amazônico, de traços muito vigorosos, destacavam-se, envolvendo-o num arco de círculo irregular, certas zonas de relevo áspero, declive

\footnotetext{
${ }^{1}$ Cunha, 1986: 6-10.

${ }^{2}$ Gadelha, 1980.

${ }^{3}$ Citando viajante inglês, Boxer, 1973: 29, citando autor inglês, o Piabiru tinha mais de 200 léguas de extensão e 5,5 pés de largura. A trilha era coberta por uma grama resistente ao fogo, o que a tornava claramente visível.
}

7 Regina Maria A. F. Gadelha. Jesuítas portugueses do Paraná... : 4-23. 
abrupto ou profunda depressão, que opunham fortes obstáculos à expansão humana e que chamaremos faixas ou centros formadores de fronteira". ${ }^{4}$

A esta unidade geográfica, comprova, compreendia outra ainda mais sólida: a da unidade cultural e econômica da ocupação humana, composta por povos diferenciados daqueles contidos pela cordilheira, representantes da civilização maia-incáica e que, como já havia também indicado Euclides da Cunha, nunca excederam as bordas da floresta tropical equatoriana, venezuelana e boliviana. Deste lado da cordilheira, porém, adentrando os limites da floresta, os grupos humanos eram outros, comprovado pelo extenso movimento migratório dos povos pré-colombianos encontrados e documentados por naturalistas e antropólogos como Alfred Métraux (1927) e Kurt Nimuendajú (1943). Refiro-me à penetração dos Karib, Aruaque, Gê, Tupi, Guarani e outras nações assinaladas nas Cartas Ânuas pelos jesuítas, e que dominavam e controlavam os territórios da América do Sul, do Orenoco ao rio da Prata. Cortesão resume o habitat e a cultura dos Tupi-Guaranis:

"Nomadismo, em país tropical rico de cursos de água e de floresta, implicava como modo de subsistência essencial, a pesca, a caça e a colheita de frutos. Não obstante, é certo que esses índios exercitavam uma agricultura de queimada, por meio da qual já tinham selecionado as mais úteis dentre as plantas dessa parte do continente. Assim, cultivavam, para citar apenas as principais, a mandioca, o milho, o algodão e o fumo. Estacionados ainda na Idade da Pedra, utilizavam para confeccionar seus instrumentos apenas a pedra, a madeira e o osso. Nus, tatuados e enfeitados com penas de aves, viviam em pequenas aldeias de malocas, dormindo em redes tecidas de algodão." 5

O mapa 2, anexo, mostra a divisória do Meridiano de Tordesilhas, negociado em 1494, e reforça a tese de Jaime Cortesão,

"Basta examinar uma carta da América do Sul cindida pelo meridiano de Tordesilhas, ainda quando este se alargasse até a ilha de Santa Catarina e ao delta amazônico, para se concluir que o território reservado aos portugueses não oferecia base suficiente e viável à formação de um Estado. Assim delimitado, esse território ficava ilaqueado e oprimido pelas duas bacias do Tocantins e do Paraná, excelentes vias de acesso e assédio, em mãos de inimigos, para o invadir e conquistar. Ao Sul a estreita faixa de terras desde o Rio de Janeiro até o litoral do actual Estado de Santa Catarina, mais que nenhuma outra seria inviável, como parte de um Estado independente. Por outro lado, o meridiano de Tordecilhas amputava com violência a vasta unidade geográfica e econômica, rodeada como uma ilha pelas bacias fluviais do Paraguai e do Madeira. O mesmo se pode afirmar com a humanidade indígenas (os tupi-guarani e os aruaque) que a habitavam e

\footnotetext{
${ }^{4}$ Cortesão, 1966, v.1: 21.

${ }^{5}$ Ibíd.: 22.
} 
oferecia tão notável contraste cultural com os quixua e os aimara dos planaltos andinos". ${ }^{6}$

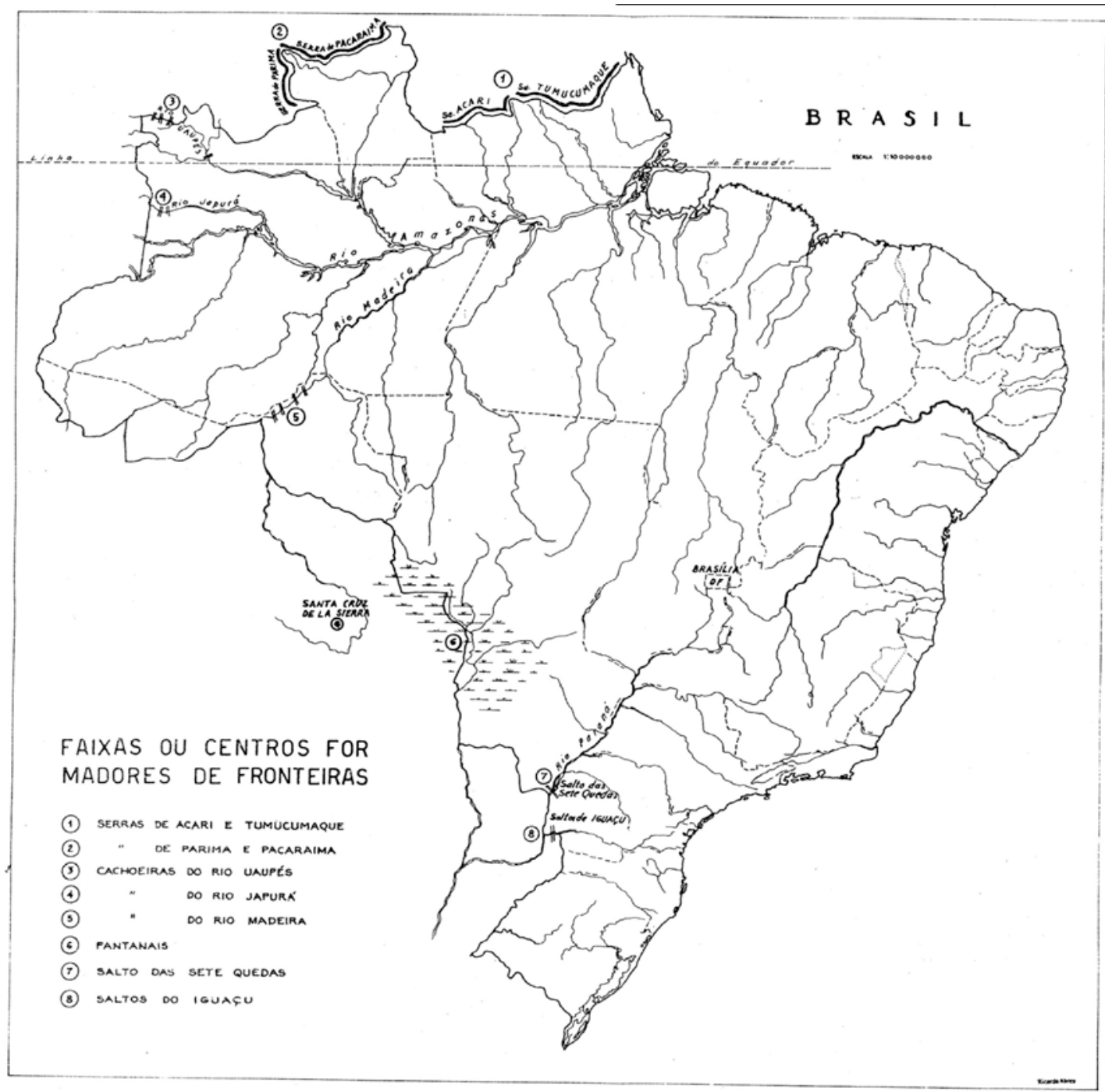

Mapa 1: Faixas ou centros formadores de fronteiras (Cortesão, 1971: Anexos).

São 8 as faixas ou centros formadores das fronteiras do Brasil, assinalados no Mapa e indicados por Cortesão: Ao norte, passando por Roraima e limite com as Guianas e a Venezuela, as serras de Acari e Tumucumaque (1) e as Serras de Parima e Paraíma (2), com a Venezuela. A noroeste, na bacia do alto rio Negro, as cachoeiras dos rios Waupés e rio Japurá (3 e 4), com Colômbia. A leste, o trecho encachoeirado do rio Madeira (5), junto à Bolívia. Ainda, com Bolívia e Paraguai, as vastas depressões alagadiças da planície de Santa Cruz de la Sierra e o Grande Pantanal matogrossense (6). Mais ao sul, limite com o Paraguai e a Argentina, o Salto das Sete Quedas sobre o rio Paraná (7), hoje desaparecido para formação do lago de Itaipu. Finalmente, os saltos do rio Iguaçu, caminho trilhado pelos índios e missioneiros do Guairá, e o Salto Grande do rio Uruguai (8)

\footnotetext{
${ }^{6}$ Cortesão, 1956, v.1: LXX-LXXI. O Meridiano não foi medido de forma aleatória. Os negociadores portugueses exigiram que a demarcação se desse atravessando a ilha de Santo Antão, extremo oeste do arquipélago de Cabo Verde.
}

9 Regina Maria A. F. Gadelha. Jesuítas portugueses do Paraná... : 4-23. 


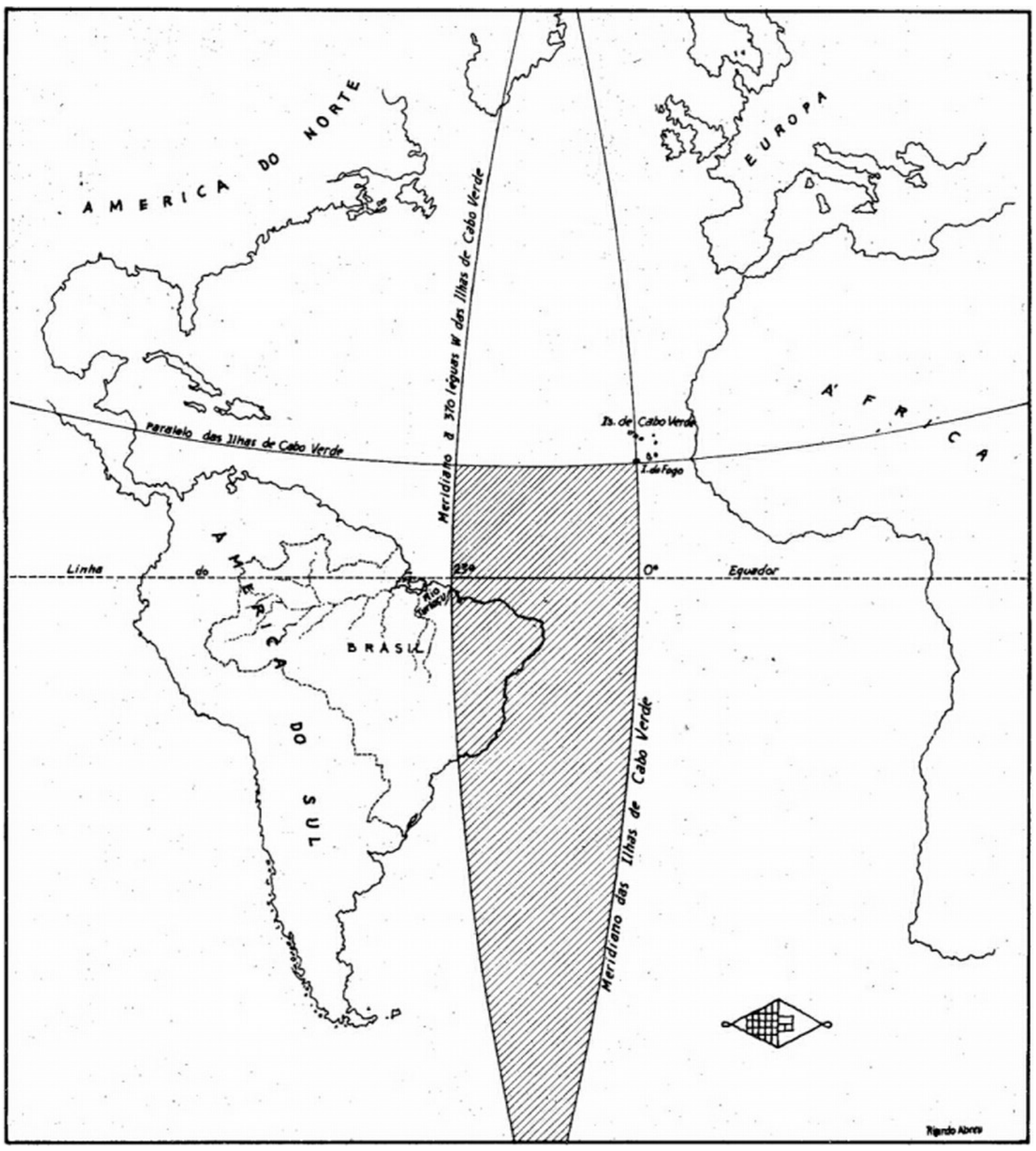

Mapa 2: Meridiano divisório entre as possessões de Portugal e Espanha fixado a oeste das ilhas de Cabo Verde (Cortesão, 1971: Anexos). 
Não quero me alongar nas citações deste autor, para quem, em relação às terras brasileiras, o Tratado já nascera “caduco”. Embora a extensão das terras pertencentes a Portugal se alargasse do delta amazônico à ilha de Santa Catarina, a realidade geográfica do território era então desconhecida dos legisladores portugueses, que negociaram o Tratado e ignoravam a unidade da grande "ilha Brasil" amazônicaplatina. $^{7}$

A Carta Atlântica de Gaspar Viegas (mapa 3), datada de 1534, é considerado o primeiro registro dos conhecimentos geográficos resultantes da expedição de Martin Afonso de Souza, enviado por D. João III na qualidade de Capitão-mor da Armada portuguesa, em 1530, para efetuar o reconhecimento da costa geral do litoral do Brasil até a bacia do rio da Prata, devendo colocar o Marco de Conquista do Rei de Portugal na desembocadura deste rio. Visualiza-se na Carta o registro do rio Paraná, ainda não nomeado, com um afluente que Cortesão presume ser o rio Tietê. No extremo sul o mapa indica a bacia do rio da Prata, limite e parte natural dos domínios do rei português.

O segundo do primeiro volume da Pauliceae Lusitana Monumenta Histórica publica os documentos relativos à viagem da armada de Martim Afonso. Entre eles o traslado original da mais antiga cópia do "Diário de Navegação" de Pero Lopes de Sousa, seu irmão, escrito de 3 de dezembro de 1530 a 24 de novembro de 1532, pertencente à Biblioteca da Ajuda (Lisboa), em que indica as causas e antecedentes da fundação de São Paulo. ${ }^{8}$ Entre a correspondência publicada, a carta de 2/agosto/1530 do Embaixador de Portugal na Espanha, Dr. Simão Afonso, dirigida a rei D. João III, informa sobre o regresso de Sebastião Caboto a Sevilha e os descobrimentos que este fizera da "descoberta pelo rio Perenae, que diziam ser de muito ouro e prata" 9 , no território considerado pelo monarca pertencente à sua Coroa. D. João III reivindicaria, de imediato, junto ao Imperador Carlos V, seu cunhado, e à sua irmã, a Imperatriz, o reconhecimento da evidência da natural possessão do Rio da Prata como sendo território português. ${ }^{10}$ A partida de Martim Afonso, em cumprimento à Ordenança Régia de 20/11/1530, com ordem para dar início ao povoamento de São Vicente e Piratininga, teria sido decorrência destes fatos. ${ }^{11}$

I - Quando do povoamento inicial de São Vicente, nos anos de 1530/1532, os Tupis e Guaranis, senhores destas terras, partilhavam o espaço hoje ocupado pelos Estados de São Paulo e Paraná, percorrendo as trilhas do Piabiru, que ligavam o Planalto paulista, dominado pelos Tupis, aos territórios dos Guaranis, cujos domínios se estendiam do

\footnotetext{
${ }^{7}$ Ibíd: v.1: LXXI. Também Gadelha, 2002: 63-80.

${ }^{8}$ Ibíd: v.1, ptes V-VIII: 431-512, "Naveguaçam q fez Po Lopez de Sousa no descobrimemto da costa do Brasil militamdo na capitania de Marti A ${ }^{\circ}$ de Sousa seu irmão: na era da emcarnaçam de 1530".

${ }^{9}$ Ibíd, v.1, ptes. I-IV: doc. 23: 104-5, "Carta do Doutor Simão Afonso para D.João III avisando do regresso de Sebastião Caboto a Sevilha. 1530-Agosto-2 (de Sevilha)".

${ }^{10}$ Idíd, docs. 35-41: 168-186. Cartas datadas de 18/9/1531 a 24/12/1531, desde Ávila e Medina do Campo, contendo conversações e as respostas do Imperador e da Imperatriz, considerando o Rio da Prata pertencer aos domínios de Castela, além de terem sido os primeiros a descobrir estas terras. Carta 40, de Medina do Campo, 14/12/1530: 184-8.

${ }^{11}$ Idíd, doc. 34: 166-168. "Carta de poder a Martim Afonso de Sousa, capitão-mor da armada que vai ao Brasil e das terras que nele descobrir, para que lhe reconheçam o dito cargo e por ele seja obedecido, conferindo-lhe jurisdição cível e criminal sobre todas as pessoas das ditas armadas e terras. 1530Novembro-20".
} 
litoral ao rio Paraná, prolongando-se até o Rio Grande do Sul, e penetrando para oeste até os contrafortes bolivianos.

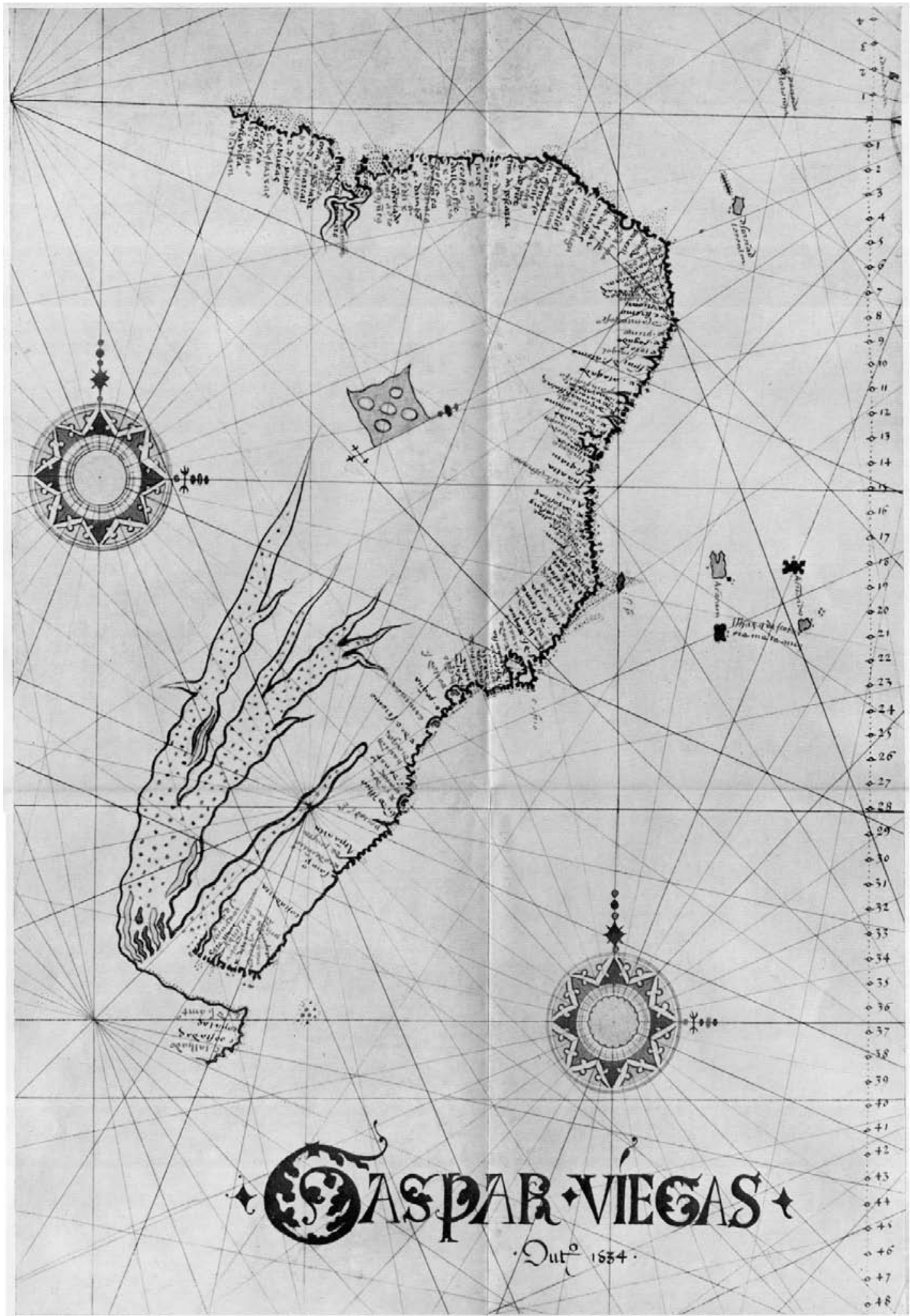

Mapa 3: Carta Atlântica de Gaspar Viegas (1534) (Cortesão, 1971: Anexos). 
Fixo a data de 1553, neste trabalho, de forma não arbitrária, por ser o marco da conquista do Guairá pelos espanhóis, comandados pelo grande governador Domingos Martinez de Irala. Mas por ser também o ano que marca o inicio da catequese nestas terras, pelos jesuítas da Província do Brasil, enviados em missão aos sertões do litoral sul, às terras dos Carijós, nome pelo qual eram conhecidos os Guaranis em São Vicente. Quanto ao ano de 1680, estabeleço este marco como indicador de uma nova etapa - a da ocupação institucionalizada dos portugueses no Rio da Prata.

Os documentos paraguaios da conquista, por sua vez, registraram em 1553 a ordenança de Irala para a fundação do povoado de San Juan, na confluência dos rios Paraná e Uruguai. O povoado, entretanto, teve pouco tempo de duração, destruído pelos Charruas e Guanás do Uruguai, que por várias décadas fecharam a passagem do rio da Prata aos espanhóis. De onde a importância estratégica da expedição realizada pelo padre Roque González ao vale do rio Uruguai, em 1622, a pedido do Governador de Buenos Aires, D. Diego de Gordara. ${ }^{12}$

1553 é também o ano da marcha de Irala sobre o Guairá, ocasião em que este conquistador logrou firmar importante aliança com vários caciques da região, que solicitavam sua proteção contra as razzias das 'malocas' dos brasílico-portugueses ou mamelucos, contra as aldeias Guaranis, em busca de escravos. Conforme escreve seu neto, Rui Díaz de Guzman, considerado o primeiro historiador do Paraguai, os objetivos da entrada de Irala no Guairá são três. Primeiro, a ocupação era considerada estratégica pelo governador, que pensava estabelecer um porto em Laguna, no litoral de Santa Catarina, a fim de assegurar esta saída para o mar e assim quebrar o isolamento dos colonos de Assunção. Segundo, o povoamento do Guairá permitiria defender a província das contínuas entradas que faziam os portugueses, aliados aos Tupis, e ao mesmo tempo viabilizar as comunicações comerciais com o Brasil, através de São Vicente, vantajoso tanto para paraguaios como para luso-brasileiros. Finalmente, no Guairá se situava a mina de ferro do Tambo, sobre o rio Cano, afluente do Piquiri. Porém sua exploração estava sujeita à prestação do serviço pessoal dos Guaranis. ${ }^{13} \mathrm{~A}$ aliança firmada com um cacique principal, Canendiyú, permitiu Garcia de Vergara, a mando de Irala, fundar a vila de Ontiveiros, às margens do rio Paraná, ainda em 1554.

Após a morte de Irala, seu genro, Rui Díaz Melgarejo, daria continuidade ao projeto em 1557, com a fundação de Ciudad Real ou Puerto Real na confluência do Paraná com o Piqueri. O povoamento desta vila se beneficiou com a migração de parte dos vizinhos de Ontiveiros, construída em sítio considerado inóspito para a saúde. Em 1576 Melgarejo fundava, ainda, nas margens do rio Ivaí, o povoado de Villa Rica del Espírito Sancto. ${ }^{14}$ As duas “cidades”, situadas em pontos estratégicos de ligação dos caminhos fluviais do Piabiru, foram importantes para a defesa do Paraguai e o controle do contrabando. Entretanto, sua existência também facilitaria maiores contactos com o Brasil e a vigilância seria muitas vezes precária, como demonstram os documentos do

\footnotetext{
12 Techo, 2005: 392-5; Techauer SJ, 2002, v.1: 82-83, indica ter sido D. Diogo de Góndora, primeiro governador da recém-fundada Governação de Buenos Aires, o idealizador da expedição de exploração do rio Uruguai, com o auxílio dos padres da Companhia.

${ }^{13}$ Discuto o tema em Gadelha, 1980: 76-77 e ss.

${ }^{14}$ Ibíd. Também meu artigo, 1981: 80-90.
} 
Arquivo de Assunção, publicados em 1949 pelo Arquivo Histórico Municipal de São Paulo, sob título Bandeirantes no Paraguai-Século XVII. ${ }^{15}$

II - Os conhecimentos dos portugueses de São Vicente, sobre o Guairá e o Paraná, permitiram Manuel da Nóbrega enviar aos Superiores, desde 1549, informações bastante precisas sobre a grandeza, o clima, a fertilidade, a abundância e as gentes do Brasil (Carta de Bahia, agosto de 1549). Como afirma, escreve de partes "mui longe donde estou, onde as mulheres [Guarani] andam vestidas ao traje de ciganas, com panos de algodão, por a terra ser mais fria que esta, a qual aqui é mui temperado." "Os gentios, continua, são de diversas castas. Uns se chamam Goianases, outros Carijós. Este é um gentio melhor que há nesta costa, aos quais foram não há muitos anos dois frades castelhanos para os ensinar; e tão bem tomaram a sua doutrina que tinham já casas de recolhimento para mulheres como freiras, e outra de homens, como de frades. $E$ isto durou muito tempo, até que o demônio levou lá uma nau de salteadores e cativaram muitos deles. Trabalhamos por recolher os salteados e alguns temos já para os levar a sua terra, com os quais irá um Padre dos nossos". " Informa, ainda, haver outra casta de gentios, que se chama Gaimurés ou Aimurés "e é gente que habita pelos matos. Nenhuma comunicação têm com os cristãos [...]. Os que se comunicam conosco até agora são duas castas: uns se chamam Tupiniques (Tupiniquins) e os outros Tupinambás”. ${ }^{17}$

A leitura da carta é enriquecida pelos esclarecimentos do padre Serafim Leite a esta edição. Segundo Leite, embora o texto original da carta de 1549 tenha se perdido, foi possível recuperar parte do original através das duas cópias existentes nos arquivos de Sevilha e Roma. Entretanto, observa, a carta contém a interpolação de acontecimentos posteriores à data original indicada, de 9 de agosto de 1549. Ou seja, ela incorpora as notícias transmitidas pelo padre Leonardo Nunes, enviado em missão aos colonos de São Vicente. Assim, inclui o relato do resgate feito por este religioso, em 1 de novembro de 1549, de “alguns escravos Carijós” capturados nas incursões dos mamelucos às aldeias Guaranis.

São, portanto, seguramente do padre Nunes as primeiras observações transmitidas por Nóbrega ao P. Inácio, sobre a moradia e os costumes dos Tupis e dos Guaranis que habitavam ao sul de São Vicente: Guayanases, Carijós, Guaimurés e outros grupos que se estendiam pelos sertões do Guairá. De mesmo as informações sobre a missão dos frades franciscanos Bernardo Armenta e Alfonso de Lebrón, enviados a Viaçá, no litoral catarinense, pelo Adelantado Alvar Nuñez Cabeza de Vaca. Estes frades teriam iniciado a catequese dos Guaranis locais por pouco tempo, antes da destruição de suas aldeias em 1543, pelos Tupis, mamelucos e portugueses de São Vicente.

\footnotetext{
15 Arquivo Histórico (1949). Os quatro primeiros documentos referem-se aos autos de processos contra mercadores portugueses, que tentaram penetrar com suas mercadorias no Guairá, pelo caminho do Piabiru, cujo acesso fora proibido para todos "portugueses, espanhóis, estrangeiros entrados pelo Porto de São Paulo”, conforme as reais cédulas de 1602 e 1618, outorgadas nos dois períodos de governos de Hernandarias de Saavedra (1602-1609 e 1615-1618), momentos de maior controle ao contrabando da região.

${ }^{16}$ Nóbrega, 1953: 57-67, em especial: 59-60.

${ }^{17}$ Ibíd.: 61.
} 
Porém, a história do Guairá também constitui uma etapa da atuação religiosa dos padres da Companhia de Jesus, de São Vicente, desde 1553 e certamente ainda em 1648, conforme registra o padre Serafim Leite, em Novas Páginas de História do Brasil (1965). A obra de Leite esclarece a ausência de fronteiras na atuação dos religiosos da Província do Brasil. Este fator também é comprovado pela obra do padre Nicolas del Techo, que assinala as diferentes origens européias dos missionários da Companhia submetidos aos superiores das Províncias do Brasil e do Paraguai ou outras partes. De fato, o autor da História da Província do Paraguai da Companhia de Jesus quando se refere aos religiosos, irmãos do Brasil, demonstra de forma clara se tratar membros de uma mesma organização, de obediência hierárquica e direção única - a Cia. de Jesus doutrinalmente apenas submetida a serviço do Papa. Equívoco dos que vêem divisão de objetivos e suposta rivalidade entre os padres das duas Províncias (Brasil e Paraguai), confundindo as instâncias religiosa e política ao fato da Companhia atuar em territórios pertencentes às monarquias de distintos Estados europeus. ${ }^{18}$

Sabemos que Manuel da Nóbrega, influenciado pelo padre Leonardo Nunes, desde 1551 pensava empreender a conversão dos índios do Paraguai. As cartas anuas do período revelam este projeto de fé, que foi compartilhado por todos os missionários da Companhia, na utopia de converterem não só os índios do Brasil como os de toda a América, mesmo à custa do martírio. Nóbrega, entretanto, foi frustrado em seu intento de enviar padres ao sul de São Vicente, por proibição expressa do governador Tomé de Sousa. Este alegara, por razões de Estado, que a ida dos padres ao Guairá causaria o despovoamento das Capitanias do Sul, além de inevitáveis atritos com a Coroa de Espanha, quando ambas as monarquias reabriam a contestação sobre os limites do Tratado de Tordesilhas. Entretanto, o próprio Tomé de Souza acreditava estar o Rio da Prata e o Paraguai situados dentro das terras pertencentes à Coroa de Portugal, conforme indica na Carta de 1 de Junho de 1553, dirigida a D. João III, em que escreve: "esta povoação que se chama a cidade de Assunção, está muito perto de São Vicente e não devem passar de 100 léguas, pela altura que se chegou claramente. Parece-nos cá a todos que esta povoação está na demarcação de V. Alteza. E se Castela isto negar, mal pode provar que é maluco seu”. Também informa: “Item de São Vicente, até o Rio da Prata estavam algumas armas de Castela em algumas partes; mandei-as tirar e deitar ao mar e pôr as [armas] de V. Alteza." 19

Esta passagem confirma a veracidade da intenção dos argumentos que contrariaram Nóbrega, ao proibir a ida dos padres de São Vicente ao Paraná, por temor da dispersão da então escassa população de colonos das capitanias do sul. Mas em 1555 Nóbrega alimentava novamente a esperança de sucesso na catequese dos Guarani do Paraguai, enviando em missão o Irmão Pero Correia, que abriria as portas para outros mais.

Entre os jesuítas portugueses, mortos em martírio para a conversão dos TupiGuarani, figura o nome deste Irmão, outrora considerado o "homem mais rico de São Vicente”, antes de entrar para a Cia. de Jesus. Recrutado pelo padre Leonardo Nunes, em 1550, foi o segundo noviço recebido no Brasil. Este sertanista português era um profundo conhecedor dos costumes e da língua brasílica. Os Tupis o consideravam "Senhor de Peruíbe", no litoral sul de São Vicente, ao pé da serra do Itatí, junto à

\footnotetext{
${ }^{18}$ Uma breve (e superficial) história da Companhia de Jesus até sua dissolução, Lacoutre, 1991, v.1.

19 "1553-Junho-1 (da Bahia). Carta de Thomé de Souza a el Rey com muitas noticias das terras do Brazil" (Cortesão, 1956: 267-74, especial: 273.
} 
passagem do Piabiru. Era considerado por eles "Chefe mais poderoso que Brás Cuba”, preposto de Martim Afonso de Souza no governo da capitania e que fundara as vilas de Santos e Santo André, esta última no Planalto. ${ }^{20}$ Correia se tornaria um dos principais instrumentos de Nóbrega na conversão dos Guaranis. Sobre as missões que realizara para atrair os Guarani, escreve Anchieta em carta datada do Colégio de Piratininga (15/08/1554), sobre a boa disposição dos Carijós do sul de São Vicente para a conversão, abrindo a possibilidade de penetração dos jesuítas ao interior de suas terras, de onde se esperava ter acesso aos gentios de outras nações. É com esta esperança que transmite aos Superiores sobre a visita de importante cacique Guarani ao Colégio de Piratininga: "E agora temos até mais do que notícias, porque veio cá um principal destes índios que chamam carijós, que é senhor daquela terra, com muitos criados seus, e não veio senão a buscar-nos para que vamos a suas terras a ensiná-los". ${ }^{21} \mathrm{Na}$ Anua de Maio-Setembro 1554 informa o falecimento deste cacique, após ter sido batizado e que viajara até São Paulo de um local distante mais de 300 milhas de São Vicente. ${ }^{22}$ A Carta evidencia que tanto os padres como os portugueses acreditavam serem os campos e as florestas do Paraná, com seus habitantes, continuidade natural dos sertões de São Vicente.

Em outra carta dirigida ao P. Ignácio, de Piratininga (agosto de 1554), informa: "Chegou-nos igualmente a nova de que os índios da ribeira [Cananéia], aonde foi enviado o Irmão Pero Correia, deram nos contrários e fizeram neles grande mortandade e cativaram a um espanhol que estava entre eles. Queira Nosso Senhor que, por meio do irmão, não o matem, porque muito o estimam os índios". ${ }^{23}$ Em 24 de agosto de 1554, Correia partira de São Vicente, em companhia do Irmão João de Sousa, para cumprir a missão recebida de Nóbrega para efetuar a conversão dos Carijós, chegando a tempo de salvar o "espanhol" de Cananéia aprisionado pelos Tupis e libertar dois prisioneiros Guaranis, informa ao P. Loyola, em 1 de setembro de $1554 .^{24}$ A anua seguinte, datada de março de 1555 , relata maiores detalhes da missão empreendida por Pero Correia e seu companheiro,

"para espalhar a palavra de Deus entre estes índios e incitá-los a juntarem-se todos numa grande aldeia que se havia de construir e assim mais facilmente poderem ser instruídos nos rudimentos e doutrina da fé cristã [...] E também, sendo possível, para conseguir algum conhecimento daqueles de que falei no último quadrimestre, chamados ibirayaras; e, não sendo possível, pregar o Evangelho de Cristo entre esses mesmos carijós e exortá-los a fazer e confirmar a paz com estes.” 25

Infelizmente Correia e João de Souza não puderam completar sua tarefa. Insuflados pelo referido "castelhano", de que Pero Correia habitava junto com os Tupis, os dois Carijós, que haviam acedido conduzir os Irmãos à sua aldeia, em missão de paz, os mataram a flechadas. A notícia, porém, somente chegou ao Colégio de

\footnotetext{
${ }^{20}$ Anchieta, 1992, t.1: 15.

21 “Carta do Irmão José de Anchieta aos Padres e Irmãos de Coimbra” (Anchieta, 1984, v. 6: 58-60, especial: 60.

22 “Quadrimestre de maio a setembro [1554], dirigida por Anchieta a Santo Inácio de Loyola”. (Ibíd: 6584, especial: 71 .

23 Ibíd: 63.

${ }^{24}$ Ibid: $65-84$.

${ }^{25}$ Ibíd: 90-108, especial: 96. "Quadrimestre de setembro a dezembro de 1554 e trimestral de janeiro a março de 1555, dirigida a Inácio de Loiola, Roma.” Piratininga, fim de março de 1555.
} 
Piratininga em fevereiro de 1555, quando os padres puderam lamentar as suas mortes. Anchieta relata na Anua:

"Não houve quem os sepultasse. Trabalharemos quanto pudermos para recolher alguns ossos ... Os índios que mataram os irmãos, embora sejam daqueles de que falei muitas vezes, chamados carijós, são ainda ferozes e indômitos, porque não tiveram trato com os cristãos e estão muito afastados da habitação dos castelhanos, que têm sob seu jugo outros da mesma raça”

“... esta nação (como dissemos noutro lugar) é muito extensa e excede em grandeza a todos, segundo julgamos.” 26

Porém, Nóbrega continuou a alimentar a vontade de levar a Palavra aos povos do Paraguai. Em Carta ao P. Loyola, de março de 1555, lamentava não poder atender aos constantes apelos que recebia dos vizinhos e autoridades do Paraguai (e mesmo de Caciques Principais) para o envio de padres do Brasil à Assunção. ${ }^{27}$ De fato, Irala enviara convite aos padres, escrevendo também ao Marquês de Mondejar, Presidente do Conselho de Índias, para que "na Europa se alcançassem cartas dos Superiores de Nóbrega, para que ele se interessasse na passagem de uma pessoa ou duas para poderem ir de São Vicente a Assunção sem perigo dos Tupis. "28

O ímpeto de Nóbrega, entretanto, foi amortecido pelo Visitador da Companhia padre Luís da Grã, com quem manteve grandes discordâncias sobre o governo da Companhia $^{29}$, e que se opunha aos seus projetos. Em 1563, respondendo ao padre Gonçalo Vaz de Melo, Provincial de Portugal, sobre as cartas de Nóbrega, de 30/07/1561, sobre o envio de padres ao Paraguai, escrevia o padre Juan Polanco, de Trento, em 25/03/1563, por comissão do Padre Geral Diego Laynes: “A 30 de Julio del 61 scrive el mesmo diversas razones pro y contra sobre la yda de algunos nuestros al Paraguay: y lo que a nuestro Padre parece es que aviendo de ir se aya licencia de su Alteza en Portugal o Allá en el Brasil de quien govierna y tiene para ello auctoridad; $y$ sin tal licentia de Portugal o de Allá que no vayan". ${ }^{30}$

Não desanimaram os religiosos do Brasil. Serafim Leite relata que, no século XVII, o padre Francisco de Morais, Reitor do Colégio do Rio de Janeiro, solicitara diversas vezes ser enviado ao Guairá para evangelizar os Guaranis. Esta vontade lhe viera desde 1628, quando era noviço da Companhia e acompanhara o padre Reitor Manuel Pacheco, do Colégio de Piratininga, em uma missão que se estendera por todo o litoral, desde São Vicente, passando pelo Paraná até Laguna dos Patos. Porém, o ano seria perturbado pela presença de Raposo Tavares na região. Em 1631, ordenado padre,

\footnotetext{
${ }^{26}$ Ibid: 100-102. Nóbrega desejara ordenar Pero Correia padre, antes de sua viagem, mas este recusara por se considerar "indigno", deixando para o retorno a ida à Bahia, relata Anchieta na longa carta de março de 1555, escrita sob o impacto dos acontecimentos.

27 “Ao P. Inácio de Loyola. Roma. (São Vicente, 25/03/1555)” (Nóbrega, 1953: 192-201).

28 “Relación Breve, con Parecer de Domingo de Irala, Gobernador de la Provincia del Rio de la Plata, ... para el Ilustrísimo Señor Marqués de Mondejar, del Consejo de su majestad, su Presidente en el Consejo de Indias”. Apud nota 3 de Serafim Leite (Nóbrega, 1953: 198-9).

29 ”Ao P. Diego Laynes, Roma. (São Vicente, 12 de Junho de 1561” (Nóbrega, 1953: 381-94).

30 “Carta do P. Juan Polanco por comissão do P. Geral Diego Laynes...” Trento, 25/03/1563 (Nóbrega, 1953: 519-23. Especial: 521.
} 
Francisco de Morais intentara realizar nova missão entre os Carijós, projeto adiado em virtude da invasão dos holandeses à capitania de Pernambuco. ${ }^{31}$

O padre Francisco de Morais certamente teve oportunidades para conhecer outros missionários da Província do Paraguai, quando estes visitaram o Colégio de São Paulo ao acompanhar os neófitos escravizados em 1628. Também em 1638 conheceu, sem dúvida, os padres António Ruiz de Montoya e Francisco Díaz Taño durante suas tumultuadas passagens por São Paulo e o Rio de Janeiro, rumo a Madri. Portanto não lhe eram desconhecidas as denúncias contra as incursões e as devastações realizadas por Raposo Tavares e seus homens no Guairá, Paraná e Itatim. Em carta de 18/01/1649, diante da desolação da Província do Guairá abandonado pelos espanhóis, insiste uma vez mais em ser enviado em missão entre os Carijós. Argumenta então: "Convinha levá-la adiante [a Missão] para que os povoadores de Santa Catarina, à sombra da Companhia, conseguissem a sua povoação; e os da Companhia, à sombra dos povoadores, tratassem da salvação das almas daqueles inumeráveis gentios, recolhendo-os lá em aldeias.” Nas palavras conclusivas de Serafim Leite,

"Há quatrocentos anos, as missões dos Carijós ocupavam o pensamento de Nóbrega e assinalou-as o sangue, também há quatro séculos, em 1554, dos Irmãos Pero Correia e João de Sousa, que tentavam forçar o passo. O cronista Anchieta diz que morreram pela Fé e pela Caridade, o que lhes daria a auréola do martírio; mas ao pormenorizar que foram mortos por instigação dum castelhano, impediu que se introduzisse a sua causa canônica. Transparecia aí um elemento político, que iria ser também com os anos um dos reflexos da auréola paulista na ocupação ulterior do sul do Brasil, do qual entretanto foram assenhoreando os espanhóis.” 32

\section{Conclusão}

As catástrofes provocadas pelos paulistas sobre as reduções das Províncias do Guairá (1627-28, 1632), do Tape (1647/48) e do Itatim (1632 e 1647) são hoje conhecidas. Esses episódios, examinados à luz da história política, ocultam, porém, outros valores ligados à mentalidade e aos fundamentos econômicos escondidos por detrás dos violentos embates, nos quais os colonos espanhóis preferiram se aliar aos luso-brasílicos invasores. De fato, a pobreza do Paraguai contrastava com a riqueza produzida pelo trabalho conduzido pelos padres nas florescentes reduções dos Guaranis, isentas da prestação do serviço pessoal. Portanto, o embate final teve como pano de fundo esta realidade, agravada pelos impedimentos régios às comunicações entre paraguaios e vicentinos. De onde a importância do reconhecimento da função militar, concedida pelo rei de Espanha à massa de guerreiros Guaranis, reduzidos nas aldeias dos Padres protegidas pelo Padroado Real. Elevadas a Doutrinas, as reduções passaram a atuar como baluarte de defesa dos interesses de Espanha, formando verdadeiro cordão de isolamento a impedir o livre trânsito e acesso destas zonas de fronteira aos espanhóis, crioulos, indígenas ou brasílico-portugueses que se aventurassem às partes extremas do território platino-paraguaio. ${ }^{33}$

\footnotetext{
${ }^{31}$ Leite, 1965: 320-321.

32 Ibíd: 325. Ainda, sobre a presença dos jesuítas do Brasil nestas regiões, o artigo de Kern. 1994: 37-56.

${ }^{33}$ Gadelha, 1980 y 1999: 233-45.
} 
O mapa 4, visualiza a posição estratégica das reduções jesuíticas nesta nova etapa de sua história até o século XVIII, completado com a fundação das reduções de Moxos e Chiquitos, na Bolívia. Ao norte, fechando o ciclo missioneiro de defesa dos territórios missioneiros, as missões dos Mainá, no extremo oeste da bacia amazônica.

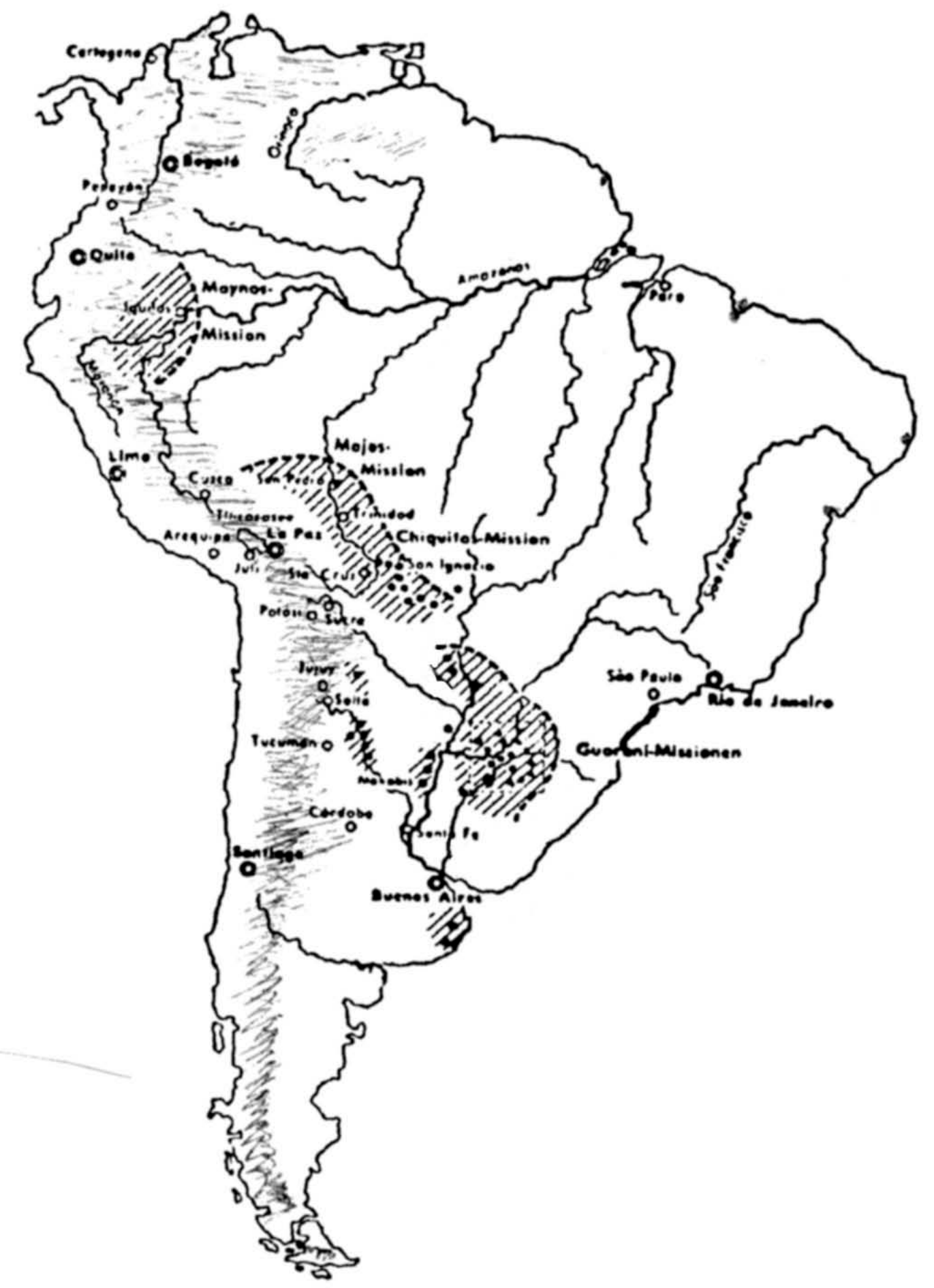

Mapa 4: Missões jesuíticas na América do Sul: Seculo XVIII. 
Na segunda metade do século XVII, portanto, a ordem imperial beneficiava o trabalho da Companhia de Jesus nas reduções do Paraguai e Rio de Prata. Em 1649, o padre Francisco Díaz Taño, incansável Procurador da Companhia, obtinha do Vice-Rei do Peru, Conde de Salvatierra, a Ordenança definitiva que elevava as reduções jesuíticoguaranis ao posto de "guarnición de frontera" e que confirmava, uma vez mais, a isenção dos Guaranis missioneiros da prestação de serviço pessoal aos encomenderos. Ademais fixava, em benefício de todas as reduções, o valor do tributo que doravante os Guaranis missioneiros pagariam ao Rei, em um peso de prata anual por cabeça. ${ }^{34} \mathrm{~A}$ Ordenança, confirmada pelas Cartas Régias de Felipe IV, consagrava a incorporação dos Guaranis Missioneiros à sociedade colonial e definia a funcionalidade social destes guerreiros promovidos a "soldados presidiários".

Embora as Províncias do Guairá e do Itatim tivessem sido abandonadas, os sobreviventes das antigas reduções ocupavam agora novos povoados, no entorno axial dos rios Paraná e Uruguai (do Rio Grande do Sul ao Uruguai, no Brasil, e atuais Províncias de Misiones e Entre-Rios, na Argentina), sob a vigilância e segura direção da Companhia. Na margem ocidental do rio Uruguai, o raio de atuação das Doutrinas se estendia pelos campos rio-grandenses, onde os padres estabeleceram duas grandes vacarias missioneiras, que beneficiavam as reduções: a Vacaria dos Pinhais, formada com o gado abandonado no Tape, em 1639, e mais ao sul, seguindo a linha das bacias dos rios Jacuí e Ibicuí até o mar, a Vacaria del Mar (proximidade de Montevidéu atual). As novas Doutrinas, que se estabeleceram neste território, ficaram conhecidas como os Sete Povos da Banda Oriental do Uruguai.

Entretanto, submetidos aos governos do Paraguai e do Rio da Prata, os presidiários Guaranis tiveram de atender às múltiplas exigências do serviço militar imposto às milícias, encarregados da defesa e exploração dos territórios das duas extensas Governações. Além de atuar na vigilância à entrada de portugueses, seus naturais inimigos, com freqüência eram requisitados para reforço do porto de Buenos Aires ou para combater as incursões de indígenas de nações inimigas como os Charrua e Minuano que percorriam os caminhos e as estradas atacando viajantes, assaltando vacarias e povoações periféricas do Rio da Prata. Também contra as nações do Chaco, que ameaçavam Corrientes e Santa Fé, e contra os Guaicuru e Paiaguá que desciam pelo rio Paraguai para ameaçarem os vizinhos de Assunção e de outros povoados. Tropas missioneiras foram igualmente utilizadas na repressão às revoltas de crioulos e mitaios paraguaios e em expedições de reconhecimento do Chaco e vales de rios como o Pilcomaio e o Paraguai. Trabalhos que custavam alguns milhares de pesos aos cofres das Doutrinas. ${ }^{35}$

Em verdade, os conflitos com sertanistas de São Paulo continuaram a ocorrer. Em 1676, os presidiários Guaranis seriam enviados para socorrerem a cidade de Villa Rica, cercada por Pedroso Xavier, e desbaratavam suas tropas, impondo grande derrota ao paulista. Os poucos vizinhos de Villa Rica, porém, abandonaram a região. Desde então os jesuítas tiveram de redobrar a vigilância dos territórios da Banda Oriental até os limites de São Vicente, procurando prevenir e dificultar a passagem das rotas do Piabiru, utilizadas pelos contrabandistas portugueses. Dois anos depois, em 1678, tropas de paulistas lideradas por Pascoal Moreira Cabral e André de Zuniga ocupavam a região abandonada de Santiago de Xerez, estabelecendo-se entre o rio Aquidauana e o curso

\footnotetext{
${ }^{34}$ Ver análise do Mss. Inédito da Coleção De Angelis, em meu artigo, 1999: 25-35.

${ }^{35}$ Remeto ao meu artigo (1994: 23-36).
} 
inferior do rio Miranda, coração do Itatim, onde fundaram o povoado de Nova Xerez. A partir desta base, instalada em pleno território dos Guaicurus e Paiaguás, passaram a controlar a passagem para o rio Paraguai, mantendo uma flotilha permanente de 80 canoas que percorriam, policiavam e devassavam o norte da governação do Paraguai. ${ }^{36}$

Entrementes o padre Nicolau del Techo, Superior das Missões do Paraná e do Uruguai, denunciava que os portugueses ameaçavam avançar até o Rio da Prata, que afirmavam pertencer à jurisdição de Portugal.

Sugeria inutilmente ao Vice-Rei de Buenos Aires a ocupação da costa do Uruguai por colonos espanhóis. Por sua vez D. Pedro, Regente de Portugal, em março de 1676 doava uma sesmaria de 75 léguas "na dita repartição do sul, a partir do marco do Rio da Prata, onde parte esta coroa para o Rio de Janeiro", aos filhos do governador do Rio de Janeiro, Salvador Correia de Sá e Benevides. ${ }^{37}$ Ao mesmo tempo reabria a questão da posse do Rio da Prata, por considerar ser este o verdadeiro limite natural das terras do Brasil e, assim, pertencente a Portugal. ${ }^{38}$ Concretizava esta antiga reivindicação, com a ordem para a construção do forte de Colônia do Sacramento (1680), em sítio escolhido acintosamente face à cidade de Buenos Aires.

As conseqüências deste fato são conhecidas. Derrotado e rendido o exército português comandado por Manuel Lobo, pelas tropas de guaranis-missioneiros a serviço de D. José de Garro, governador de Buenos Aires, o comandante português foi desagravado por Real Cédula de 1681, em cumprimento ao Tratado Provisório entre Portugal e Espanha. Carlos II ordenava não apenas a imediata retratação de D. José de Garro perante o comandante português como a reconstrução do forte, com devolução das armas, munições, canhões e artilharias à custa do Governador. A respeito deste episódio, escrevi em 1994: "Grave erro, que levaria a Espanha perder, alguns anos depois, parte do extenso território do Uruguai para os portugueses." 39

Em 1684 os portugueses iniciavam a ocupação do litoral sul de Santa Catarina, com a fundação do povoado de Laguna, no local em que se erigia uma capela construída e periodicamente visitada pelos jesuítas de Piratininga, em missões realizadas desde os tempos do Provinciado de José de Anchieta. Laguna era considerada ponto nevrálgico para as operações militares do Uruguai. Em 1737, os portugueses fundavam o Presídio de Rio Grande de São Pedro, posse avançada garantida com a construção do forte de S. Miguel, ao sul da lagoa do Mirim. Finalmente, em 1742, a penetração lusa se firmava no Rio Grande, com a fundação da vila de Porto Alegre, às margens do rio Guaíba.

Entre 1746 e 1749 o governo português enviava a estas regiões, 4000 casais de açorianos e madeirenses, para serem assentados em pequenos povoados com 60 casais cada, "desde o rio de S.Francisco do Sul até o serro de S. Miguel" ${ }^{40}$, iniciando o povoamento permanente do Paraná a Santo Antonio do Viamão, no Rio Grande do Sul. Nesta última localidade os colonos estabeleceram as primeiras estâncias formadas com o gado abandonado (ou roubado) das vacarias missioneiras. Realizava-se, assim, a ocupação econômica e civil de regiões abandonadas pelos jesuítas espanhóis e não

\footnotetext{
${ }^{36}$ Cortesão,1971, v.2:139-40.

${ }^{37}$ Ibíd: 139. Maiores detalhes sobre a doação da sesmaria a Martim Correia de Sá (1º Visconde de Asseca) e João Correia de Sá (Boxer, 1973: 306-16).

${ }^{38}$ Cortesão, 1971.

${ }^{39}$ Gadelha, 1994: 32.

${ }^{40}$ Cortesão,1971, v.2: 245.
}

21 Regina Maria A. F. Gadelha. Jesuítas portugueses do Paraná... : 4-23. 
ocupadas pelos escassos vizinhos paraguaios, base da arguição futura do uti posseditis, com a qual o brasileiro Alexandre de Guzmão obteve finalmente, em 1750, a assinatura do Tratado de Madri e a posse da região dos Sete Povos para o Brasil.

\section{Referências}

Anchieta SJ, José de (1984), Cartas. Correspondência Ativa e Passiva. 2.e. São Paulo: Edições Loyola.

Anchieta SJ, José de (1992), Doutrina Cristã. São Paulo: Edições Loyola.

Arquivo Histórico (1949), Bandeirantes no Paraguai. Século XVII. São Paulo: Prefeitura Municipal de São Paulo-Depto. de Cultura.

Boxer, C. R. (1973), Salvador de Sá e a luta pelo Brasil e Angola: 1602-1686. Rio de Janeiro: Cia. Editora Nacional/EDUSP.

Cortesão, Jaime (1956), Pauliceae Lusitana Monumenta Histórica. Organizado e Prefaciado por J. Cortesão. Lisboa: Real Gabinete Português de Leitura do Rio de Janeiro, 1956. $3 \mathrm{v}$.

Cortesão, Jaime (1966), Raposo Tavares e a formação territorial do Brasil. Lisboa: Portugália.

Cortesão, Jaime (1971), História do Brasil nos Velhos Mapas, Rio de Janeiro: MRE/Instituto Rio Branco, + Anexos.

Cunha, Euclides da (1986), Um paraíso perdido. Ensaios, estudos e pronunciamentos sobre a Amazônia. Rio de Janeiro: José Olympio, 1986. "Conflito inevitável”.

Gadelha, Regina Maria A. F. (1980), As Missões Jesuíticas do Itatim. Estruturas sócioeconômicas do Paraguai colonial: Séculos XVI-XVII. Rio de Janeiro: Paz e Terra.

Gadelha, Regina Maria A. F. (1981), “A presença dos jesuítas no Guairá”. IV Simpósio Nacional de Estudos Missioneiros. Santa Rosa: FFCL Dom Bosco [Anais].

Gadelha, Regina Maria A. F. (1994) “Os Guarani Missioneiros nos Presídios da Fronteira Rio-Platense”. V Jornadas Internacionales sobre las Misiones Jesuíticas. Montevidéo: MEC.

Gadelha, Regina Maria A. F. (1999), "Jesuítas e Guarani: A experiência missional triunfante”. In: Gadelha, Regina A.F. Missões Guarani: Impacto na sociedade contemporânea. São Paulo: EDUC.

Gadelha, Regina Maria A.F. (1980), As Missões Jesuíticas do Itatim. Estruturas sócioeconômicas do Paraguai colonial: séculos XVI-XVII. São Paulo: Paz e Terra.

Gadelha, Regina Maria A.F. (2002), "Conquista e ocupação da Amazônia: a fronteira norte do Brasil”. Estudos Avançados. São Paulo: USP, 45: 63-80. Mai-Ago.

Kern, Arno A. (1994), “Guaranis e Jesuítas: Fronteiras Culturais e Políticas do Rio da Prata colonial”. V Jornadas Internacionales sobre las Misiones Jesuíticas. Montevidéo: MEC.

Lacoutre, Jean (1991), Jésuites. Une multibiographie. Paris: Seul, 1991. v.1: Les Conquérants.

Leite SJ, Serafim (1965), Novas páginas de História do Brasil. Ed. Completa. São Paulo: Cia. Editora Nacional. 
Nóbrega SJ, Manuel (1953), Cartas do Brasil e mais escritos do P. Manuel da Nóbrega. (Opera Omnia), Introdução e notas históricas e críticas de Serafim Leite, SJ. Coimbra: Universidade.

Techauer SJ, Carlos (2002), História do Rio Grande do Sul dos dois primeiros séculos. 2.e. Porto Alegre: UNISINOS.

Techo SJ, Nicolas del (2005), Historia de la Província del Paraguay de la Compañía de Jesús. Nueva ed. Prólogo de Bartomeu Meliá, SJ. Asunción: CEPAG/FONDEC. 